\title{
A Selfie e a pós-fotografia: considerações psicológicas
}

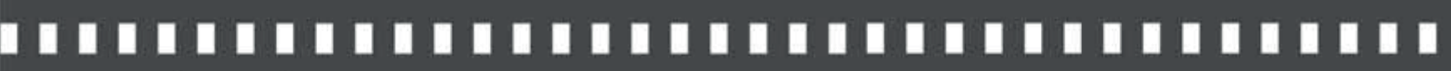

Filipe Mattos de Salles

Artigo recebido em: 20/08/2017

Artigo aprovado em: 27/06/2018

D0I 10.5433/1984-7939.2018v14n24p13 


\title{
A Selfie e a pós-fotografia: considerações psicológicas
}

\author{
The selfie and the post-photography: psychological \\ considerations
}

Filipe Mattos de Salles**

\begin{abstract}
Resumo: A chamada 'Pós-Fotografia' é um conceito desenvolvido por Fontcuberta (2011, 2012) para o entendimento dos fenômenos visuais da era digital, incluindo o gênero 'Selfie', tanto na sua produção quanto em seu uso. Entretanto, nem sempre é possivel identificar no resultado deste gênero uma intenção deliberada em questionar os limites da significação fotográfica. Destarte, a análise da Selfie parece ter maior afinidade com uma razão psíquica do que com uma possivel teoria da comunicação, sendo suas características particulares decorrências das intenções psicológicas. Por este viés, o presente trabalho fará uma análise deste fenômeno com base na psicologia junguiana, que, acreditamos, oferece ferramentas ontológicas para o entendimento do fenômeno em sua razão intrínseca: nós.
\end{abstract}

Palavras-chave: Fotografia. Fotografia digital. Pósfotografia. Selfie.

Abstract: The so-called 'Post-Photography' is a concept developed by Fontcuberta $(2011,2012)$ for understanding the visual phenomena of the digital era, including the 'Selfie' genre, both in its production and in its use. However, it is not always possible to identify in the result of this genre a deliberate intention to question the limits of photographic meaning. Thus, the Selfie's analysis seems to have greater affinity with a psychic reason than with a possible theory of communication, its particular characteristics being the result of psychological

*Doutor pela PUC/SP. Fotógrafo e cineasta, formado em cinema pela FAAP. Professor de fotografia no Departamento de Midialogia e Artes Visuais do IA/ UNICAMP. 
intentions. From this approach, the present work will analyze the phenomenon based on Jungian psychology, which we believe offers ontological tools for the understanding of the phenomenon in its intrinsic reason: us.

Key words: Photography. Digital photography. Postphotography. Selfie.

\section{Introdução}

Em artigo publicado no Brasil pela revista ZUM em 7 de dezembro de 2016, intitulado "Dança Sélfica", Joan Fontcuberta e Martin Parr tecem considerações sobre o fenômeno da Selfie, gênero fotográfico que consiste basicamente em retratos posados em que o retratado é o próprio autor da foto. Este tipo de fotografia se tornou extremamente popular com o advento das câmeras em dispositivos móveis, que, pelo tamanho e facilidade de uso, permitem uma rápida exposição em praticamente qualquer situação de luz, tendo por intenção mostrar alguma condição ou atividade que o autorretratado gostaria de compartilhar. O gênero recheia grande parte do enorme arcabouço contido nas redes sociais, já que seu objetivo é, justamente, o compartilhamento, se não instantâneo, pelo menos o mais breve possível. $\mathrm{O}$ artigo coloca tal gênero numa condição diferenciada de interpretação poética, sendo reconhecido como um ato "pós-fotográfico", porque, segundo sua natureza, "a câmera desgruda do olho, afasta-se sujeito que a controlava e, à distância de um braço estendido, volta-se para fotografar justamente este sujeito" (FONTCUBERTA; PARR, 2016). Tal fato "transforma a atávica concepção da fotografia de um 'Isto aconteceu' para 'eu estava 
ali"” (FONTCUBERTA; PARR, 2016), substituindo a "certificação de um acontecimento pela certificação da nossa presença no acontecimento" (FONTCUBERTA; PARR, 2016). O assunto selfie em questão é meramente um pretexto para também justificar a ideia de uma nova perspectiva no fazer fotográfico, situando a era digital como um diferencial marcante no resultado técnico e estético da imagem fotográfica, e por isso mesmo chamada de 'pós-fotografia'.

\section{O que é Pós-Fotografia?}

Entretanto, faz-se necessário antes contextualizar corretamente o sentido do termo, já que se trata de um conceito relativamente recente e que ainda suscita múltiplas interpretações. Esta proposição tem sido utilizada com maior frequência desde 2011, quando Fontcuberta publicou no jornal La Vanguardia de Barcelona o texto Por um manifesto pós-fotográfico, e desde então empregado por diferentes autores, como Robert Shore (2014) PostPhotography: The Artist with a Camera, e David Levi-Strauss (2014) Words not spent today buy smaller images tomorrow, sempre na acepção original de que a "pós-fotografia nada mais é que a fotografia adaptada à nossa vida on-line", uma "estética do acesso" (FONTCUBERTA, 2011). Tal ponto de vista, evidentemente, traz uma séria de consequências capazes de moldar nossa relação com as imagens com as quais convivemos, e que, em última análise, se traduzem em usos diversos, mas que na verdade, em si mesmos, não são diferentes dos usos tradicionais com que a fotografia sempre nos serviu (informação, memória, apreciação artística), se não 
fosse pela questão da quantidade: os clicks fotográficos se tornaram desenfreados, e muitas vezes inconsequentes, levando muitos artistas a questionar esta sociedade adicta por imagens através de práticas pouco ortodoxas, como apropriação de imagens panópticas das mais variadas fontes (redes sociais, câmeras de segurança, Google Earth, etc.), para traduzir fins estéticos determinados. Ou ainda, o uso de softwares e/ou algoritmos específicos para gerar correções, distorções e aberrações na imagem, utilizar deliberadamente erros de leitura nos arquivos (Glitch Art), ou mesmo completar fundos situando os indivíduos retratados em cenários das quais não fizeram parte. O próprio Fontcuberta (2012), em outra obra de bastante repercussão, A câmera de Pandora, cita um grande número de experiências estéticas relacionadas à fotografia neste panorama diverso inserido no contexto de questionamento do papel e da veracidade da imagem fotográfica digital, em oposição à fotografia química, considerando que a primeira "se inscreve" e a segunda "se escreve". E chama a tudo isso de 'pós-fotografia'. (FONTCUBERTA, 2012, p. 189).

\section{A Necessidade de um Recorte no Conceito}

A problemática deste tratamento não é, em si, a nomenclatura, Fontcuberta também cita 'Fotografia 2.0'1, mas a

${ }^{1}$ Fotografia 2.0 também é um termo questionável, na medida em que depende de como é feita a análise histórica de sua evolução. Se levarmos em conta os primeiros processos artesanais, a Fotografia 2.0 seria a fotografia industrializada que permitiu o amplo acesso do público, principalmente através da câmera Kodak, e, neste caso, a fotografia digital seria a 3.0. 
ilusão que se trata de um novo consenso universal na prática da fotografia em todos os seus níveis de atuação, e que estaria abalando conceitos e fundamentos na produção de imagens fotográficas tanto para usuários amadores como profissionais. É preciso fazer um recorte bem delineado na apresentação da ideia de um inédito "fazer" e "pensar" a fotografia, uma vez que os exemplos citados por Fontcuberta dizem respeito apenas a uma utilização puramente estética, através da inquietação de artistas frente a uma saturação visual que se apresenta modernamente, e da qual estamos invariavelmente imersos.

Assim sendo, uma análise em que se trate o devido recorte, nos mostra que a fotografia em si como meio de produção comercial em seus diversos segmentos continua inabalável em sua crença de ilusão visual: a publicidade, a moda, a fotografia social e de eventos e mesmo o fotojornalismo, mantém o hábito de suprir seus paradigmas com forjações visuais deliberadas, convencendo seu público consumidor (eventualmente espectadores) de que aquela imagem traduz um perfeito ideal da realidade que se almeja vender. Nenhum casal de noivos quer fotos de pessoas infelizes em seu casamento; nenhum empresário ou comerciante quer ver seu produto parecer desfavorecido em uma campanha. Todos os jornais, virtuais ou impressos, precisam de leitores, e isso determina, em última análise, o uso que se dá à fotografia convencional. Isto sempre foi assim, inclusive no meio puramente pictórico anterior à descoberta da fotografia, e a tecnologia empregada é sempre tendo como objetivo ampliar o engodo coletivo. Em meu trabalho anterior (SALLES, 2016), proponho justamente que a imagem não é um crivo nem critério de realidade, e sim o testemunho de que ali 
havia uma ideia a ser representada, e a ideia se sobrepõe à realidade figurativa, que é mera delusão visual. Ora, neste sentido, é forçoso notar que em nada de essencial (considerando a essência no mesmo sentido de âmago ou noema da imagem) (BARTHES, 1984), mudou na fotografia analógica para a digital. E, todas as facilidades que se podem enunciar advindas dos aplicativos e softwares especialmente criados para manipular a imagem codificada, nada mais são que ferramentas melhoradas que permitem formas mais convincentes para os mesmos fins. A razão disso parte do pressuposto que a imagem tem uma intenção deliberada ao ser realizada (justamente sua ideia), e em nome desta ideia, todos os processos tecnológicos foram desenvolvidos ou apropriados. É notório, neste contexto, o fato de que sempre se editou fotografias, mesmo que, numa realidade analógica química, tais práticas se mostrem imperfeitas, demoradas e caras, dado o grau de precisão artesanal necessária. Considerando justamente estes aspectos (perfeição, rapidez e custo), a fotografia digital apenas deu continuidade ao mesmo processo de forma mais rápida, barata e eficiente. Comercialmente, um grande alívio, apesar da rapidez gerar também diversas imperfeições - Fontcuberta (2012) detalha essa faceta peculiar no capítulo 'O mistério do mamilo desaparecido'.

O único grande entrave que a fotografia digital enfrenta que é radicalmente diferente da relação que tínhamos com a fotografia química, é a problemática do armazenamento a longo prazo, dado que o arquivo digital, por ser na verdade um mero impulso elétrico codificado, é extremamente frágil na medida em que depende de hardwares ainda pouco confiáveis, ou suscetíveis de falha na leitura, roubo, perda ou armazenamento corrompido 
(HDs, Cartões de memória, Pen-Drives) ${ }^{2}$. A seriedade desta questão deixou desde pequenos fotógrafos até empresários da industria do entretenimento perplexos, e que levou a própria Academia de Ciências Cinematográficas de Hollywood a elaborar um texto oficial de recomendação quanto a práticas de armazenamento mais seguras. Tal texto, intitulado $O$ Dilema Digital, foi distribuído gratuitamente para cinematecas do mundo inteiro, inclusive a de São Paulo, que traduziu e deixou disponível em seu site ${ }^{3}$.

A conclusão óbvia é que a mudança de paradigma que realmente teve relevância na fotografia comercial decaiu sobre o modus operandi da fotografia, basicamente seu fluxo de trabalho, e muito pouco sobre a estética ou o conceito artístico decorrente ou ainda envolvido no processo. Basta pensar que todas os modismos do gênero 'fotografia social', que tratam da fundamental e básica tarefa de registrar momentos pessoais (casamentos, batizados, aniversários, festas em geral), mobilizou tendências as mais diversas e inusitadas, como o Trash the Dress, Pré-Wedding, e até o registro da Lua-de-Mel (há algum tempo atrás, uma impensável), sem que nenhum destes gêneros tenham algum tipo de necessidade tecnológica exclusiva que torne a câmera ou algum processo digital imprescindível. O mesmo se pode dizer da fotografia publicitária,

${ }^{2}$ Há muitos casos corriqueiros de fotógrafos que chegaram a perder todo o portfólio digital por falha ou descuido no armazenamento.

${ }^{3} \mathrm{http}: / /$ cinemateca.gov.br/sites/default/files/Dilema_Digital_1_PTBR.pdf

${ }^{4}$ Talvez seja importante mencionar, neste contexto, que há um certo mito corrente, principalmente entre um público leigo nos assuntos técnicos de fotografia, de que tudo pode ser construído ou corrigido na edição das imagens. Não apenas é uma informação falaciosa, mas também, muito pelo contrário, é consenso geral entre os fotógrafos e produtores publicitários que é extremamente contraproducente gastar tempo e dinheiro tentando ajustar um erro de captação, de forma que, salvo imagens que deliberadamente tenham sido previamente pensadas para serem editadas, o desejável é obter um original perfeito, ou seja, na hora do clique e não depois dele. 
que, no âmbito de seu quotidiano de produção, possui apenas e tão somente a prerrogativa de utilizar as facilidades digitais na edição e pós-produção de suas campanhas visuais ${ }^{4}$. A captação da imagem em si independe do processo (analógico ou digital), e este último acaba sendo preferido também pela facilidade de compartilhamento e redução de custo. Já no fotojornalismo este purismo é mais radical. Apesar de edições serem possíveis e efetivamente realizadas, é pressuposto que a imagem deva ser "idônea", mesmo sendo impossível um olhar absolutamente isento, e a razão do uso da imagem digital recai sobre a rapidez e o custo.

O resultado é que o dia-a-dia de um fotógrafo profissional só pode ser considerado pós-fotografia de um ponto de vista mecanicista, qualificando a maneira de trabalhar e não o resultado fotográfico.

\section{A Questão da Selfie}

Mas e quanto ao fotógrafo amador? Uma das bandeiras do manifesto da pós-fotografia recai justamente nas práticas mais comuns do uso de câmeras portáteis e dispositivos móveis por usuários desqualificados, e que enchem as timelines das redes sociais de selfies e memes cuja variedade é tão grande quanto o número de pessoas que realizam tais imagens. E este ponto parece ser nevrálgico no que diz respeito a tais inquietações. $\mathrm{O}$ fenômeno da selfie é encarado com viés epistemológico, como se fosse realmente um prenúncio de uma nova era da fotografia. Mas um olhar mais atento nos revela outra faceta, um pouco mais distante deste ideal acadêmico da comunicação e das artes, que já é constatado em vários trabalhos sobre o tema publicados em anais recentes: os 
artigos de Leonardo Pastor Rodrigues (2016) e Isaac Pipano (2016) nos lembram que sempre se fizeram selfies, já que o autorretrato é uma das mais antigas manifestações pictóricas, e a própria fotografia tem inúmeros exemplos desde seus primórdios (Bayard se autofotografou nu em protesto, já que o governo francês não o reconheceu como inventor da fotografia, assim como o próprio Daguerre também se fotografou em seu daguerreótipo). Apesar de, em ambos os artigos, haver um consenso sobre a diferenciação entre a selfie e o autorretrato, dado o aspecto ontológico de realização espontânea do fenômeno, é possível considera-los manifestações únicas cuja diferença reside unicamente na forma tecnológica envolvida. Assim sendo, no decorrer da evolução da industria fotográfica, a mudança que se verifica é um reflexo do avanço tecnológico sobre as câmeras, que permitem, gradativamente, sempre tomadas de pose com maior precisão, facilidade e menor tempo.

Figura 1 - Hippolyte Bayard (1801-1887): the drowned man (1840).

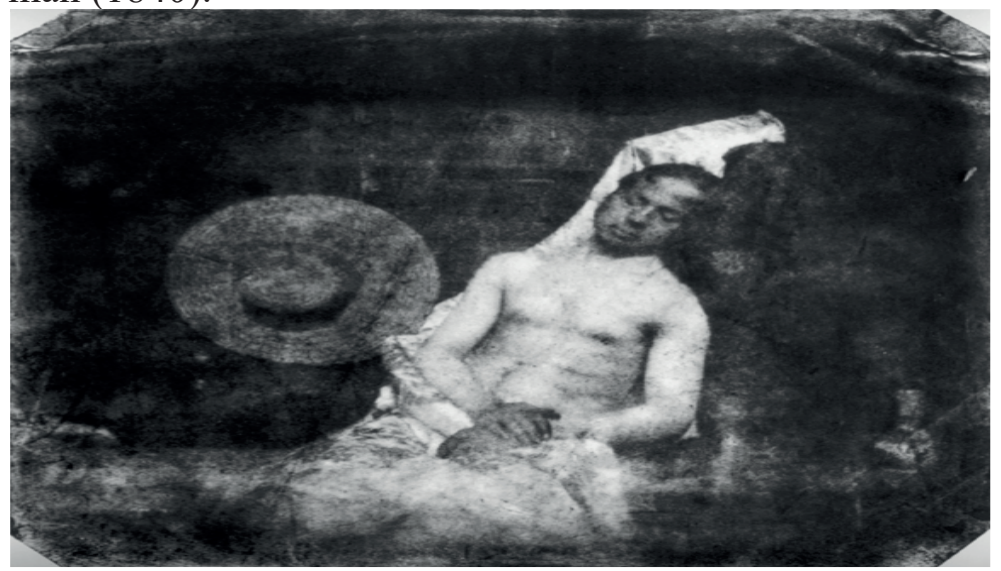

Fonte: Willette (2015). 
Figura 2 - Self-Portrait.

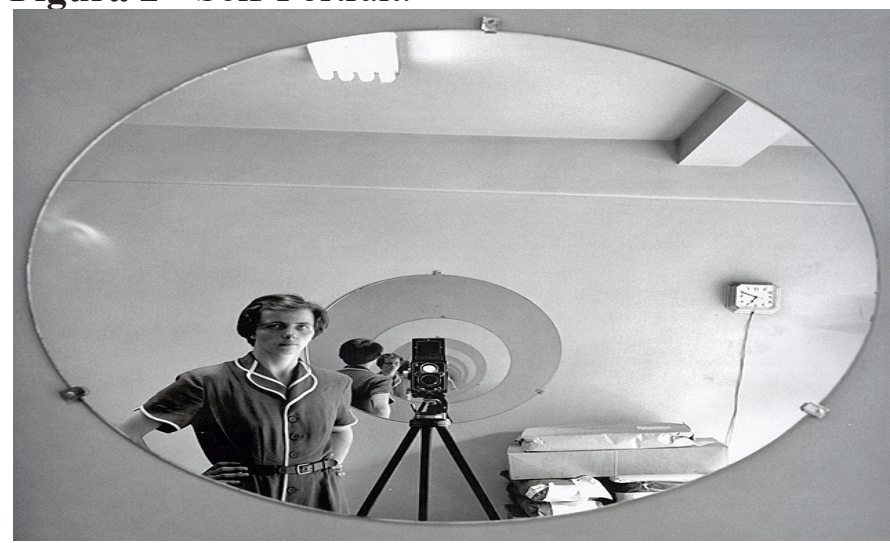

Fonte: Vivian Maier (1955).

Figura 3 - Selfie de um grupo de alunos de fotografia na FCAD/CEUNSP (2014).

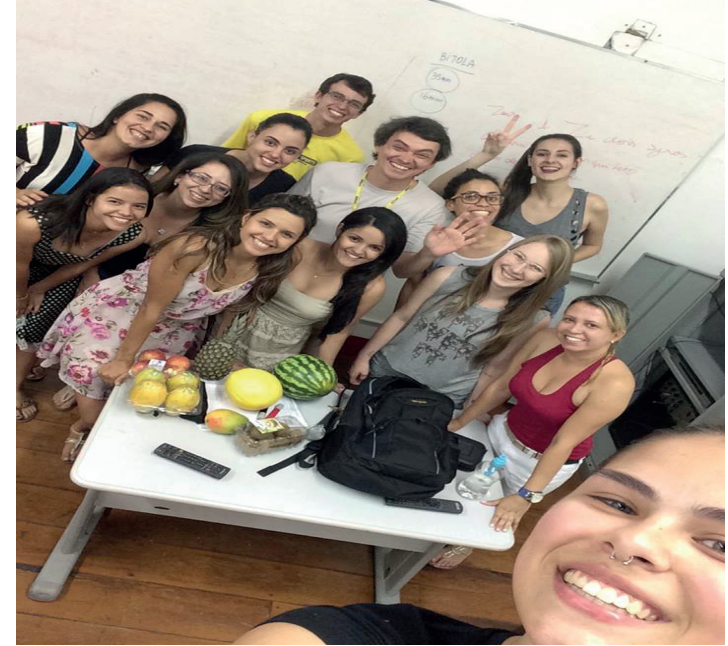

Fonte: Fotografia de Isabela Correia.

A invenção da câmera com filme em rolo por George Eastman em 1888 já permitia selfies através de espelhos, prática que adentrou o século XX com enorme popularidade (conforme o 
exemplo da fotógrafa Vivian Maier acima), e depois, com a invenção das câmeras acopladas a dispositivos portáteis, até mesmo o espelho, bem como tripé e temporizador, passaram a ser dispensáveis ${ }^{5}$, e em seu lugar um aparelho facilitador foi desenvolvido: o pau de selfie. Isso tornou a selfie uma prática simples e corriqueira, ao ponto dos dispositivos já saírem de fábrica programados para esta modalidade. Basicamente, o número de selfies é enorme muito mais porque é enorme o número de câmeras disponíveis do que por um fenômeno puramente conceitual ou artístico em torno da fotografia. Praticamente todas as pessoas do mundo que possuem telefones móveis, possuem, exatamente por isso, uma câmera portátil disponível a qualquer momento. A questão que se interpõe é se a prática da selfie é uma ação em consequência da tecnologia ou se foi a tecnologia que libertou anseios reprimidos que já estavam presentes no imaginário coletivo. Neste sentido, uma análise preliminar aponta a tecnologia como um divisor de águas, mas não porque dela veio a selfie, mas porque, antes, quando um transeunte encontrava algo ou alguém interessante que quisesse registrar e compartilhar, deveria: 1) estar munido de uma câmera; 2) a câmera teria que ter poses livres no filme virgem; 3) ser de fácil manuseio; 4) ao mesmo tempo que deveria ter boa qualidade ótica; 5) as condições de luz deveriam ser favoráveis; e 6) teria que pedir a alguém que fizesse o retrato, eventualmente alguém desconhecido ou inapto a operar a câmera. Evidentemente, essa pequena lista de condições constituía uma grande barreira para manifestação plena do fenômeno selfie, tal qual hoje vemos. Mas, uma vez que a tecnologia resolveu todos ${ }^{5}$ Mesmo o autor deste artigo tem selfies de 2004 e 2005 tiradas ainda com câmera analógica $35 \mathrm{~mm}$, uma Nikon FE com lente $24 \mathrm{~mm}$, sem uso de espelho nem pau de selfie. 
estes pormenores (quantas vezes, na era analógica, nos deparamos com cenas surpreendentes e falamos para nós mesmos: 'se ao menos tivesse uma câmera!'), um eventual anseio que já era latente se atualizou com tamanha força que temos por resultado exatamente o que vemos hoje: a desmedida produção de imagens cotidianas, que possui, além do mais, uma válvula de escape, seu principal veículo de disseminação, os aplicativos de redes sociais.

Portanto, a confusão entre os resultados práticos, que provavelmente levou não apenas Fontcuberta, mas também outros pesquisadores a admitir uma mudança de paradigma substancial, se dá por dois motivos: um seria o aspecto tecnológico que permite a realização espontânea da imagem sélfica praticamente sem nenhum conhecimento técnico ou estético, e a segunda seria a sua inflação numérica: a exacerbada quantidade que assusta. Entretanto, verificamos que o a imagem ainda é a mesma porque a razão que as une também é a mesma: um autorretrato como os citados nos exemplos (Bayard, Vivian Maier) e uma selfie (descontando a facilidade de uso dos dispositivos móveis, que permitem poses mais descontraídas) tem em comum a intenção primeira de compartilhar tal imagem de algum modo (e que forma um complexo psicocibernético com as redes sociais), o que justifica a ideia de que são a mesma ação em razões tecnológicas diferentes, além de também indicar uma necessidade psicológica por trás do ato ${ }^{6}$.

${ }^{6}$ Vivian Maier, por exemplo, foi um curioso caso avesso, na qual nunca mostrou seu trabalho em vida, tendo sido descoberta acidentalmente quando um corretor de imóveis adquiriu boa parte de seu portfolio postumamente num leilão, e muitas de suas imagens ainda estavam em filmes não revelados. Neste caso, é razoável supor que, apesar de não existir uma intenção de compartilhar a imagem, há uma necessidade psicológica intrínseca à realização da selfie da mesma forma. 
Neste ponto, ressalta então a questão da quantidade, que chega a intimidar por seus números astronômicos: Fontcuberta (2011) relata que a quantidade de imagens que correspondiam à tag sunset no flicker, passou de 541.795 em 2006 para 8.700.317 em 2011. Rodrigues (2016) menciona que o uso da palavra Selfie aumentou 17000\% em um ano (de 2012 para 2013), e em 2014 o Google estimou a quantidade de 93 milhões de selfies tiradas por dia em dispositivos Android. Os números causam assombro: sem dúvida nos instiga a imaginar que algo mudou na relação estabelecida com a fotografia, pelo menos do ponto de vista do usuário comum, o que seria atestado justamente por uma mudança de comportamento chamada de 'pós-fotografia'.

Então por que, neste contexto, a fotografia amadora ou mesmo a profissional de relações comerciais, anteriormente citadas, não estabelecem a mesma relação sujeito-objeto com esta pós-fotografia, ao ponto de passar-lhes despercebido este universo, e o tratamento dado à fotografia ser basicamente o mesmo, acrescentando apenas requintes de edição e preocupações de fluxo de trabalho e armazenamento?

\section{Ontologia do Fenômeno Pós-fotográfico}

Seguindo a mesma razão de meu trabalho anterior, esta pergunta também pode ser respondida se levarmos em conta que o que move o mundo fotográfico não é a câmera ou o objeto-fotografia em si - muito menos o assunto fotografado, e sim o dispositivo que opera na retaguarda da câmera, com o olho no visor. Este sim é o responsável pelas escolhas da câmera, pela resultante da formafotografia e, consequentemente, tudo o que se pode pensar dela. 
Este dispositivo, já de muito tempo conhecido por homo sapiens, é a última instância que responde diretamente pelo comportamento de nosso mundo, incluindo o da representação. E, dentro dele, ainda, o que o move de forma mais profunda, a psique.

Como entender, portanto, um fenômeno como o das selfies (ou dos memes) sem passar pela análise dos aspectos psíquicos que nos guiam? Conforme já exposto, a selfie não é uma ideia nova, até mesmo a pintura produziu 'selfies', como a deliciosa paródia do auto-retrato de Norman Rockwell:

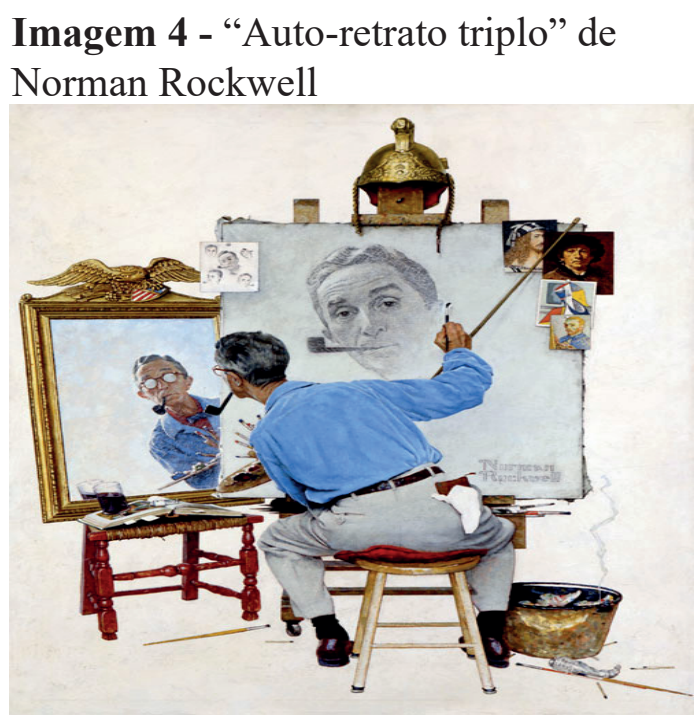

Fonte: Norman Rockwell Museum (1959).

E, portanto, o que mais clama por nossa atenção não é o fato em si, mas, conforme já mencionado, sua exacerbada quantidade, que decorre muito mais de uma possibilidade inerente (já que é um processo que depende de um grau tecnológico específico) do que de uma tendência estética genérica. Em outras palavras, o ser humano 
sempre quis se representar, e hoje há uma tecnologia que oferece esta possibilidade de forma rápida, fácil e a custo praticamente zero - um verdadeiro convite à sua realização.

A razão da selfie está, portanto, no comportamento qualitativo do ser humano. Por que se representar? E - claro, só isto não basta - por que se representar tanto?

Talvez Fontcuberta esteja certo no que concerne à análise de que o autor da selfie queira atestar sua presença num local ou num evento ('eu estava ali'), compondo assim uma cena narcisista, mas este fato não está, necessariamente, em oposição ao 'isso foi assim' da fotografia documental. Isso porque na fotografia que se pretende documental (como notoriamente o fotojornalismo), a ideia de que alguém apertou o botão da câmera é subliminar, no sentido de que se pressupõe a presença do fotógrafo no evento. Imagens emblemáticas deste gênero sempre suscitam admiração pela perspicácia do fotógrafo em conseguir, justamente, um momento único que imortaliza ou descreve visualmente a cena com maior abrangência ou precisão:

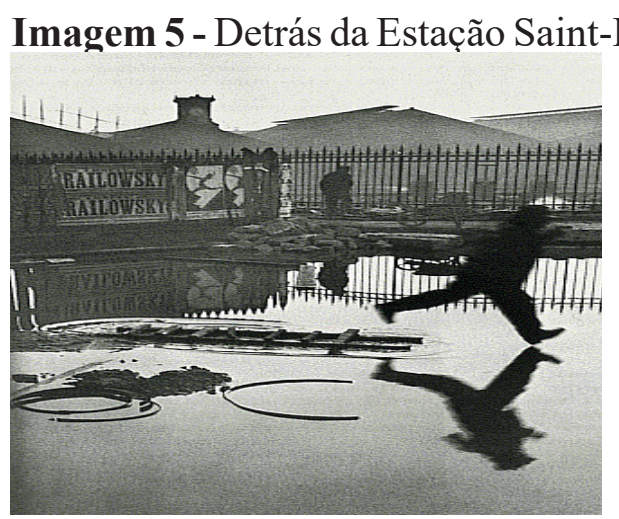

Fonte: Cartier-Bresson (2004). 
Neste mesmo contexto está a admiração pela capacidade de congelar o tempo no 'momento decisivo' de Cartier-Bresson (2004), e todas estas facetas são implicações de um mesmo fenômeno, da busca pela representação ideal. Meu trabalho anterior (SALLES, 2016) versa sobre tais aspectos, e, na mesma medida, é possível reutilizar este percurso lógico para entender o fenômeno das 'pós-fotografia'.

Por se tratar de uma representação induzida, onde está implícita a intenção de significar, a selfie pode ser analisada tanto do ponto de vista proposto por Fontcuberta, da imagem como objeto em que representaria um último degrau na escala significante (depois do registro "puro" e do registro encenado), tanto pelo viés da imagem em seu estado ideal, antes de acontecer, e que está, portanto ainda na esfera do pensamento. E, para adentrar neste obscuro estado interior, é preciso um suporte da psicologia, que permite então estabelecer relações entre o eu e um objeto qualquer, que, neste caso, é a imagem.

Carl Gustav Jung (1987), em um de seus mais interessantes trabalhos, $O E$ Eu e o Inconsciente, aborda, entre outras coisas, o aspecto dual entre eu e sociedade, e assim nos abre uma importante janela interior que permite visualizar mecanismos negligenciados por nosso próprio medo e incompreensão. Em suas palavras:

Sempre partimos do pressuposto ingênuo de que somos senhores em nossa própria casa. Deveríamos no acostumar, entretanto, com a ideia de que [...] vivemos em uma espécie de casa cujas portas e janelas se abrem para o mundo: os objetos e conteúdos deste último atuam sobre nós, mas não nos pertencem"(JUNG, 1987, p. 81). 
Esta prerrogativa abre nuances que subdividem o eu e sua intrincada rede, por vezes obscura em demasia, mas que permite perceber este aspecto duplo entre aquilo que convencionou chamar de 'Persona', e o conceito de 'anima' e 'animus'. A Persona seria um "segmento arbitrário da psique coletiva.", um aspecto da personalidade por nós eleita como representação externa de nosso eu, "uma imagem ideal, à qual o indivíduo aspira moldar-se",[...] um complicado sistema de relação entre a consciência individual e a sociedade; uma espécie de máscara destinada [...] a ocultar a verdadeira natureza do indivíduo" (JUNG, 1987, p. 32). Já os conceitos de anima e animus representam um substrato muito mais profundo, já que a experiência humana só é possível dada a "presença de uma predisposição subjetiva", ou uma "estrutura psíquica inata”, sendo eles, portanto, "o reconhecimento psicológico da existência de um complexo psíquico semiconsciente" (JUNG, 1987, p. 66). Este é o complexo que modula a energia psíquica que move nossas ações, sendo ele em grande parte inconsciente, e por vezes chamado genericamente de 'alma', apesar de, segundo o próprio Jung, o uso do termo não ter nenhuma acepção filosófica ou religiosa. Esta também se apresenta de forma dual: "A anima, sendo feminina, é figura que compensa a consciência masculina. $\mathrm{Na}$ mulher, a figura compensadora é de caráter masculino, e pode ser designada pelo nome de animus." (JUNG, 1987, p. 81).

Tais conceitos se apresentam extremamente úteis neste tipo de análise, em que uma tipologia visual não fica à mercê de uma categorização baseada no objeto final, e sim na razão de sua concepção. Em outras palavras, a selfie nos parece uma atualização objetiva da persona em reiterar um dado estado aparente, ou de 
tornar público - e é neste aspecto que entra a tal pós-fotografia - a máscara para o maior número de pessoas possível. É a auge da reafirmação da fantasia da personalidade, ou a maneira como queremos e precisamos nos mostrar para a sociedade. Pela análise psicológica competente, fica bastante evidente que não se trata de mera reprodução narcisista, e nem (apenas) um fenômeno exclusivo da comunicação contemporânea. A era da internet e das redes sociais nada mais faz que evidenciar um aspecto intrínseco da persona humana, tornando visível a necessidade preexistente, diria até natural, do ser humano em procurar um espelho ideal para justificar sua existência para a sociedade. "A persona não passa de uma máscara da psique coletiva. [...] ela representa um compromisso entre indivíduo e sociedade acerca daquilo que alguém parece ser: nome, título, ocupação, isto ou aquilo"(JUNG, 1987, p. 32).

A lógica que sustenta a compulsão moderna de autorepresentação não poderia, portanto, ser completamente entendida apenas como fenômeno sociológico ou da comunicação, visto que se trata de uma ação espontânea, observada naturalmente sem a intervenção direta de nenhum sistema comercial que pudesse gerar algum fetiche sobre uma sociedade de consumo. Muito pelo contrário, os aplicativos e os dispositivos móveis é que se adaptaram comercialmente à exigência do público consumidor. A razão da selfie remonta a aspectos arquetípicos da natureza humana que já estavam presentes nas análises de Platão (1999), como a imagem-representação que traduz um ideal, e Aristóteles (1973, p. 445). 'Imitar é congênito no homem', e 'Os homens se comprazem no imitado'. Acrescenta-se a isso a pressão psíquica que nossa sociedade enfrenta de fabricar mitos modernos para suprir a 
necessidade de um parâmetro arquetípico em nosso inconsciente, conforme atesta Jung: "Os conteúdos psíquicos transpessoais não são inertes ou mortos [...]. São entidades vivas que exercem sua força de atração sobre a consciência" (JUNG, 1987, p. 20).

Portanto a selfie é um fenômeno (se é que este é o termo mais adequado) para designar a era em que este império da persona está em plena manifestação, de forma exacerbada, porém lícita, mas que não justificaria em si uma denominação que fizesse referencia a uma nova era fotográfica. É uma era dos extremos: anima versus persona no ponto de conflito, em cuja tensão se estabelece, timidamente o si-mesmo. É portanto, tanto natural como inevitável, que se use dos atributos tecnológicos disponíveis para que este embate consiga chegar a seu objetivo, o equilíbrio da psique. "Da consideração das exigências do mundo interno e do mundo externo, ou melhor, do conflito entre ambos, procederá o possível e o necessário" (JUNG, 1987, p. 81). A imagem tem, neste sentido, função primordial para estabelecer a dinâmica energética deste processo, pois sem ela o aspecto impalpável do si-mesmo não poderia encontrar apoio, dada a configuração tridimensional de nossa capacidade cognitiva. Em última análise, de um ponto de vista psicológico, a razão da 'moda selfie' é uma necessidade de afirmação da persona perante a sociedade, o que denota, em nosso tempo, a fragilidade emocional e incapacidade de viver de forma independente frente a um mundo instável e, portanto, num grau de mutabilidade psíquica que beira o descontrole. Destarte, é um fenômeno que deve ser aceito como salutar, dado seu potencial de regular o equilíbrio, ainda que ilusório, no intrincado jogo de tensões que, para usar a nomenclatura freudiana, prevalece entre id e ego. 
Mas todo este limite de fronteiras sobre a chamada pósfotografia não necessariamente se aplica ao fotógrafo-artista que possui intenções estéticas mais profundas, e aí entramos num universo diferente, que testa os limites dos conceitos préestabelecidos, e evoca um olhar poético. Não que eles não estejam sujeitos aos mesmos processos psíquicos internos, pelo contrário, não apenas estão, como são mais sensíveis à eles, mas para estes, a noção de que existe uma pós-fotografia é importante justamente para poder estabelecer uma relação estética com o fazer fotográfico e questioná-lo ao mesmo tempo. Seria, a despeito de tal panorama, um modo pragmático de entender como opera o mundo fotográfico contemporâneo. E, neste ponto, nosso recorte absorve sem problemas o conceito de pós-fotografia, pois para o questionamento estético, existe a necessidade de reconhecimento de fatores formais que norteiam determinadas condições de realização artística. E, como a arte se expressa pela forma, ela passa a ser importante como elemento inteligível de expressão. Isso fica bastante claro quando aberrações técnicas produzidas por erros de leitura passam a ser consideradas formas estéticas dignas de apreciação (Glitch Art), e aí estamos adentrando um terreno em que se faz quase imprescindível delinear tal contexto, e neste sentido cabe considerar uma fronteira de eras, dando razão ao manifesto pós-fotográfico.

\section{Conclusão}

Falar genericamente num mundo 'pós-fotográfico' é tratar de maneira absoluta uma tendência unilateral e relativa, pois seus atributos só podem ser realmente medidos em quem está no 
papel de questionar os limites do pensar a imagem e a fotografia. Isso se atribui muito mais à sensibilidade dos artistas-fotógrafos e aos pesquisadores da área de artes e comunicação do que aos usuários comuns que fazem ainda da fotografia uma atividade comercialmente viável. Neste sentido, é forçoso notar que, em função de uma mesma lógica psíquica, a resultante materializada também é produto de lógica similar, e esta é a razão pela qual, durante praticamente toda a história da representação (que se confunde com a história da própria humanidade), tanto a necessidade quanto a intenção que dela se extrai, se mantém inabalável. Apenas a construção da imagem que é feita de maneiras as mais diversas, em função das formas que determinadas tecnologias e/ou tendências estéticas ou modismos prevalecem. E este também é um aspecto ilusório que tende a confundir nossos sentidos, pois que acabam por tomar a parte pelo todo, numa metonímia oculta em que pensamos ver a razão na forma e não na ideia que a gerou ${ }^{7}$. As possibilidades tecnológicas (por exemplo, neste caso a fotografia digital, em oposição à analógica), são meramente ferramentas que permitem novas formas para expressar os mesmos arquétipos. E os artistas, que trabalham exatamente com a dicotomia ideia-forma, parece útil que haja uma nomenclatura específica no que diz respeito à mudança de um paradigma, ainda que seja formal. E, apenas neste sentido, cabe inaugurar uma era pós-fotográfica.

\section{Referências}

ARISTÓTELES. Poética. São Paulo: Nova Cultural, 1973. 
BARTHES, Rolan. A câmera clara: nota sobre a fotografia. São Paulo: Nova Fronteira, 1984

CARTIER-BRESSON, Henri. O imaginário segundo a natureza. Barcelona: G.Gilli, 2004.

FONTCUBERTA, Joan. A câmera de Pandora. São Paulo: G. Gilli, 2012.

FONTCUBERTA, Joan. Por um manifesto pós-fotográfico. Tradução de Gabriel Pereira 2011. Studium, Campinas, n. 36, 2011. Disponível em: <http://www.studium.iar.unicamp.br/36/7/>. Acesso em: 10 maio 2017.

FONTCUBERTA, Joan; PARR, Martin. Dança sélfica: Revista Zum, São Paulo, n. 11, 7 dez. 2016. Disponível em: <https:// revistazum.com.br/revista-zum-11/danca-selfica/>. Acesso em: 10 maio 2017.

JUNG, Carl Gustav. O eu e o inconsciente. São Paulo: Vozes, 1987.

LEVI-STRAUSS, David. Words not spent today; buy smaller images tomorrow: essays on the present and future of photography. New York: Aperture, 2014.

MAIER, Vivian. Self-portrait. 5 May, 1955. Disponível em: $<$ http://www.vivianmaier.com/gallery/self-portraits/\#slide-31>. Acesso em: 10 maio 2017.

NORMAN ROCKWELL MUSEUM. Presents the brain and the portrait with Dr. Donald B. Giddon. Indianapolis: Curtis Publishing, 1959. Disponível em: <https://www.nrm. 
org/2018/07/69746/>. Acesso em: 10 maio 2017.

PIPANO, Isaac. Espelhos opacos, espelhos reflexos: selfies e autorrepresentação na era dos smartphones. In: ENCONTRO ANUAL DA COMPÓS, 25., 2016, Goiânia. Anais... Goiânia: Universidade Federal de Goiás, 2016. Disponível em: $<$ http://www.compos.org.br/biblioteca/templatexxvcompos isaacpipano_3351.pdf>. Acesso em: 10 maio 2017.

PLATÃO. A República. São Paulo: Nova Cultural, 1999. (Os Pensadores).

RODRIGUES, Leonardo Pastor Bernardes. Imagens de si: experiência e intimidade em torno da prática contemporânea do selfie. In: ENCONTRO ANUAL DA COMPÓS, 25., 2016, Goiânia. Anais... Goiânia: Universidade Federal de Goiás, 2016. Disponível em: <http://www.compos.org.br/biblioteca/ imagensdesi-gtciber-leonardopastor_3277.pdf $>$. Acesso em: 10 maio 2017.

SALLES, Filipe. A ideia-imagem: forma e representação na fotografia moderna. Curitiba: Appris, 2016.

SHORE, Robert. Post-photography: the artist with a camera. London: L. King, 2014.

WILLETTE, Jeanne. Hippolyte Bayard (1801-1887). 2015. Disponível em: <https://arthistoryunstuffed.com/hipploytebayard-1801-1887/>. Acesso em: 10 maio 2017. 